\title{
Saberes y mediaciones pedagógicas en contingencia sanitaria. El caso de una educadora en un contexto marginal
}

Pedagogical knowledge and mediations in health contingency. The case of an educator in a marginal context

\section{Volumen 21, Número 3 \\ Setiembre - Diciembre \\ pp. 1-33}

Rosa Lilian Martínez-Barradas

Citar este documento según modelo APA

Martínez-Barradas, Rosa. (2021). Saberes y mediaciones pedagógicas en contingencia sanitaria. El caso de una educadora en un contexto marginal. Revista Actualidades Investigativas en Educación, 21(3), 1-33. Doi. 10.15517/aie.v21i3.46459 


\section{Saberes y mediaciones pedagógicas en contingencia sanitaria. El caso de una educadora en un contexto marginal}

Pedagogical knowledge and mediations in health contingency. The case of an educator in a marginal context

\section{Rosa Lilian Martínez Barradas ${ }^{1}$}

Resumen: La educación preescolar como primer eslabón de la educación obligatoria en México es fundamental para cimentar las bases cognitivas, físicas y axiológicas en el individuo. Este artículo sistematiza el seguimiento a una educadora con 20 años de experiencia, quien actualmente se desempeña en una institución educativa ubicada en un contexto urbano con alta marginación social. Interesa reconocer los saberes docentes emergentes para atender las situaciones que este contexto le demanda, así como las estrategias y mediaciones que le han permitido salvaguardar los propósitos formativos del nivel educativo, sobre todo en lo que el confinamiento causado por el SARS-CoV-2 ha provocado. El seguimiento se realizó en el periodo comprendido entre septiembre de 2019 y marzo de 2021, bajo la metodología de estudio de caso que, posicionado en el paradigma cualitativo, utiliza el Modelo de Análisis de las Interacciones Escolares E-P-R y el concepto de saber docente de Tardif. El análisis parte del cruce de datos de las entrevistas (a profundidad y semiestructuradas) iniciadas en el mes de septiembre de 2019 -periodo previo a la pandemia-, con los registros de observación de ocho sesiones remotas realizadas durante el confinamiento social. Los resultados permiten visibilizar cómo la pandemia ha estimulado la creación de situaciones de enseñanza en donde las mediaciones principales son el uso de los lenguajes oral y gestual. También se detectan saberes centrados en la importancia de reconocer al otro desde el aprendizaje situado, evidenciando adecuaciones que buscan interacciones más cercanas, a pesar de estar mediadas por una pantalla. Igualmente, se afirma que estos hallazgos requieren de mayor estudio y análisis por parte del colectivo docente, en atención a la estrategia metodológica.

Palabras clave: Saberes docentes, educación preescolar, mediación pedagógica

Abstract: Early childhood education is the first link in compulsory education in Mexico. This educational level is fundamental in children's development to increase cognitive, physical and axiological bases. This article systematize the follow-up of a-20 years of experience Mexican educator. She is currently attending preschool children in an urban context with high social marginalization. It is interesting to recognize the emerging teaching knowledge to attend situations that this context demands; as well as the strategies and mediations that have allowed it to safeguard the formative purposes of the educational level, especially in what the confinement caused by SARS-CoV-2 has caused. The follow-up was carried out from the period between September 2019 and March 2021. It is a case study positioned in the qualitative paradigm, uses the Model of Analysis of School Interactions E-P-R and Tardif Teaching Knowledge conception. The results were derived from the cross-referencing of data obtained from the interviews (in-depth and semi-structured) started in September 2019 -the period before the pandemic-, with observation logs of eight remote sessions performed during social confinement. The results show how the pandemic has created and recreated teaching situations based on the use of teaching knowledge. The main mediations are the use of oral and gestural languages as transversal content. The research has detected knowledge focused on the importance of recognizing the other from situated learning, evidenced in constant adjustments that bring them closer, despite the fact that the interactions are mediated by a screen. Likewise, it is stated and these findings require further study and analysis by teaching community in attention to the methodological strategy.

Keywords: Teacher knowledge, early childhood education, pedagogical mediation

\footnotetext{
${ }^{1}$ Docente de la Benemérita Escuela Normal Veracruzana "Enrique C. Rébsamen", Xalapa, Veracruz, México. Maestra en educación con especialidad en cognición de procesos de enseñanza-aprendizaje (Tecnológico de Monterrey). Candidata a Doctora en Educación (Universidad Autónoma de Tlaxcala). Orcid: https://orcid.org/0000-0001-5296-6868
}

Dirección electrónica: lilianmb84@gmail.com

Artículo recibido: 18 de marzo, 2021

Enviado a corrección: 7 de junio, 2021

Aprobado: 16 de agosto, 2021 


\section{Introducción}

La educación preescolar es uno de los niveles educativos que, desde finales del siglo XIX, ha ido forjando camino a partir de las aportaciones de pedagogos como Federico Froebel y Enrique Pestalozzi. Varios países latinoamericanos como Argentina, Chile, Colombia, México y Brasil la han ido incorporando en sus currículos desde hace más de 150 años. Los primeros espacios fueron creados como programas de tipo asistencial para después conformarse en instituciones educativas (Peralta y Fujimoto, 1998) conocidas en la actualidad como jardines de infantes. En México se les nombra jardines de niños.

En el Sistema Educativo Mexicano, la educación preescolar es un derecho para la niñez entre los tres y seis años de edad. En 2002 se decretó como obligatoria y debía cubrir tres grados. Lo anterior le genera al Estado la necesidad de abrir más escuelas que permitan atender a la población que se inserta. Tal situación aún no ha sido resuelta: existen entidades federativas, como el caso de Veracruz, que no han logrado la cobertura total para este nivel educativo. Los datos estadísticos nacionales reportan que $63.3 \%$ de la población de 3 a 5 años de edad asiste a una institución perteneciente a este nivel educativo (Instituto Nacional de Estadística y Geografía [INEGI], 2020). Sin embargo, la obligatoriedad del nivel ha conseguido un incremento relevante en la matrícula; para 2017, se observa un crecimiento de $77 \%$. Eran atendidos casi 4931966 preescolares, por 234635 docentes en 89939 planteles escolares (Instituto Nacional para la Evaluación de la Educación [INEE], 2019).

Frente a lo anterior se observa que, a pesar de algunos esfuerzos del Estado por atender necesidades y mejorar las condiciones que garanticen los derechos del niño y de la niña, sigue habiendo aspectos que no han logrado bajar los índices de vulnerabilidad en ciertas poblaciones, los cuales se reflejan de manera palpable en el rezago educativo.

En este estudio interesa focalizar la atención en un escenario urbano-marginado para observar si las características sociales, económicas y culturales que bloquean el acceso a los recursos para desarrollarse de manera equitativa (Doré, 2008; Enríquez, 2011) influyen en la intervención docente de una educadora mexicana en el marco de la pandemia ocasionada por el SARS-CoV-2.

Es así como se intenta dar a conocer, mediante un estudio de caso con un enfoque cualitativo, bajo un paradigma interpretativo y de alcance descriptivo, la manera en que esta docente ha logrado, a través de sus saberes, mediar sus procesos de enseñanza ante las vicisitudes del contexto marginal donde se desarrollan los educandos a quienes atiende. Las preguntas que guían dicho estudio son: ¿qué saberes docentes se evidencian durante las 
intervenciones de una educadora en un contexto urbano-marginal? ¿Cuáles son las implicaciones que el contexto urbano-marginal tiene sobre sus procesos de enseñanza durante el confinamiento? ¿Cuáles son las principales mediaciones que la educadora tuvo que crear para atender a su alumnado en la emergencia de una educación remota?

En congruencia con la estrategia metodológica de estudio de caso, esta investigación recurre al uso de las entrevistas semiestructuradas y a profundidad con la intención de conocer desde la propia voz de la educadora: quién es, cómo ha ido construyendo su propia identidad docente y sus saberes, cuáles son los significados que le da a la educación preescolar y cuál es la concepción que tiene acerca del niño en edad preescolar. Estas entrevistas se realizaron a partir del mes de septiembre de 2019 -periodo previo a la pandemia- y se finalizaron en el mes de abril del 2020, justo un mes después de que el Gobierno de la República Mexicana anunció la estrategia nacional de Sana Distancia en atención a los protocolos promovidos por la Organización Mundial de la Salud (OMS).

Esta investigación utiliza el modelo Epistemológico-Pragmático-Relacional (E-P-R) como propuesta de análisis de la actividad docente planteada por Isabel Vinatier, el cual se fundamenta teóricamente en el interaccionismo y en la didáctica profesional (Vinatier, 2013). Para tal efecto, la intervención docente fue observada de manera sincrónica durante las sesiones mediadas por el servicio de Zoom. Se hizo un registro de la observación y, como apoyo, se recuperan los videos de las intervenciones. Cabe resaltar que tal modelo tuvo que ser adaptado en función del tipo de interacciones observadas a partir del confinamiento. La principal modificación se deriva de la no presencialidad, factor que transforma el concepto de interacción cara a cara.

El aislamiento que se está viviendo en los países latinoamericanos ha evidenciado de una manera contundente la falta de recursos, estrategias, tecnología y estilos de docencia que se han limitado a dar respuesta a lo que las autoridades inmediatas y los medios de comunicación masiva exigen o esperan de la educación, sin realmente atender a las necesidades básicas de aprendizaje en cada nivel educativo desde lo que los propios contextos demandan.

La pandemia visibiliza una desnudez que se ha tenido que ir arropando en la creatividad del profesorado y en la disposición y los recursos de la comunidad educativa en la que se desempeñe. Por tanto, y más allá de las estadísticas y resultados oficiales que se reportan en los diferentes medios de comunicación, con este estudio se pretende recuperar testimonios directos y datos empíricos que describan la manera en que una educadora ha tratado de cubrir 
los propósitos educativos del nivel, a través de una enseñanza remota, que tiene como principal escenario su propia casa.

El caso aquí descrito permite conocer, a partir de cuestionamientos y reflexiones sobre su actuar, algunas de las preocupaciones que han llevado a la docente a la creación de estrategias de enseñanza para atender las particularidades o necesidades del grupo atendido durante el ciclo escolar 2020-2021, aspectos que le han permitido reinventarse momento a momento para tratar de generar ambientes genuinos de aprendizaje.

\subsection{Escenario urbano-marginado}

En las dos últimas décadas, los escenarios marginados han sido analizados en países latinoamericanos tales como Perú (Doré, 2008) y Argentina (Enríquez, 2011), en estudios que permiten visualizar ciertos aspectos en común en relación con las condiciones que se ofertan en los diferentes niveles educativos. Se habla de segmentación y de algunas problemáticas de infraestructura y de algunas carencias de servicios básicos, en relación con el aspecto educativo. Las escuelas, por lo general, dentro de estos escenarios, son públicas.

Interesa recuperar a México como el macrocontexto en el cual se inscribe esta investigación. Este país cuenta con una población de 126014024 habitantes (INEGI, 2020) y ocupa el decimoprimer lugar de densidad poblacional en el mundo. Particularmente, y en función del tema que ocupa a esta investigación, interesa destacar los datos estadísticos en materia de educación, los cuales indican que la población de 15 años o más presenta las siguientes características: $4.5 \%$ se encuentra sin escolaridad, $49.3 \%$ está estudiando la educación básica, ${ }^{2} 24 \%$ está cursando la educación media superior y $21.6 \%$ está realizando sus estudios en educación superior (INEGI, 2020).

Respecto del preescolar, nivel educativo en el que se centra este estudio, se considera importante comentar que la obligatoriedad del nivel, establecida en 2002 (Poder Ejecutivo, 2002), ha generado cambios significativos tales como el incremento de la matrícula en los últimos 10 años (INEE, 2019). De los jardines de niños, $50 \%$ son de modalidad general, ${ }^{3} 20 \%$

\footnotetext{
${ }^{2}$ La educación básica en México incluye los niveles de preescolar, primaria y secundaria desde 1992, tal como se dio a conocer en el Acuerdo Nacional para la Modernización de la Educación Básica (Diario Oficial de la Federación, 12 de mayo de 1992).

${ }^{3}$ La modalidad general está integrada por los planteles urbanos públicos, las escuelas privadas y las escuelas rurales -no unitarias y unitarias (INEE, 2010).
} 
es atendido por el Consejo Nacional de Fomento Educativo (Conafe), ${ }^{4}$ 16.4\% son escuelas privadas y $11 \%$ son indígenas. La mitad de las instituciones cuenta al menos con un aula multigrado; las escuelas comunitarias, atendidas por el Conafe, son las que presentan mayor porcentaje con esta condición (83.5\%), seguidas por la modalidad indígena (76.5\%), según reporte del INEE (2018).

Se observa que es en los planteles urbanos públicos donde se concentra la mayor matrícula de alumnos (55.8\%) y $44.6 \%$ de la totalidad de docentes, seguidos por las escuelas privadas y las rurales -no unitarias y unitarias-. La educación indígena corresponde a 8.3\% de la matrícula general, atendida por $8.1 \%$ de docentes. El Conafe atiende a 2.8 por ciento.

El contexto urbano-marginal presenta un déficit de recursos básicos para la vivienda, relacionado directamente con la atención a altas densidades poblacionales. Para Enríquez (2011), este contexto "implica un escenario social en el cual sus habitantes no cuentan con las condiciones necesarias que les garanticen una plena integración social” (p. 54).

Cabe resaltar que, en muchas ocasiones, la migración de las poblaciones rurales es la que alimenta la densidad poblacional de este tipo de escenarios. Hablar de educación en este contexto permite visualizar a estudiantes que viven situaciones de rezago, algunas derivadas de procesos cada vez más frecuentes de desintegración familiar, motivadas por la migración de la madre o del padre de familia y por la incorporación de la mujer al campo laboral.

Tenti (1995) plantea que la sumatoria de pobreza social y pobreza de recursos educativos genera una baja calidad en los procesos de enseñanza y aprendizaje, y alude a un círculo vicioso entre pobreza social y enseñanza. También existen algunas posturas que refieren lo contrario y dan a la escuela o a la educación la potestad de generar el cambio, desde la perspectiva social de esta institución (Redondo y Thisted, 1997). Tal visión permite ver las condiciones contextuales como un aliciente para buscar la transformación de sus realidades.

\subsection{La educación preescolar en Veracruz}

El estado de Veracruz es una entidad federativa caracterizada por su diversidad cultural. Su densidad poblacional lo coloca en el decimoprimer lugar del país, con 113 habitantes por

\footnotetext{
4 El Conafe es un organismo descentralizado que brinda servicios educativos en los niveles inicial y básico a poblaciones de niños y de adolescentes con marginación o rezago social. Cabe aclarar que el servicio es otorgado por jóvenes de entre 16 y 29 años, quienes deben haber concluido al menos su educación secundaria.
} 
kilómetro cuadrado. Tiene una población total de 8112505 habitantes, con 4203365 mujeres y 3909140 hombres, lo que le hace ocupar el tercer lugar a nivel nacional en este rubro.

Históricamente Veracruz se ha destacado por sus innovaciones pedagógicas. En 1883, es fundada por Enrique Laubscher la primera escuela de párvulos en Orizaba. En 1885 se instaura el normalismo moderno con la Academia Normal de Orizaba, también con la participación de Laubscher. En 1886 se funda en la ciudad de Xalapa la Escuela Normal Veracruzana en el Convento de San Ignacio, bajo la dirección de Enrique C. Rébsamen (Martínez-Barradas, 2017). Las ideas pedagógicas propuestas por Pestalozzi y Froebel son recuperadas en México y en Veracruz desde los inicios del siglo XX (Galván, 2019).

Veracruz tiene 7648 instituciones de educación preescolar, atendidas por 17087 docentes, quienes son responsables de una matrícula escolar de 256950 alumnos (Secretaría de Educación de Veracruz, 2019).

\subsubsection{Microescenarios: escuela y aula urbano-marginadas}

La institución educativa se describe con base en los datos recabados en la entrevista realizada a la directora durante el único encuentro sostenido dentro de la institución (EUMED.18092019), en el registro de observación llevado a cabo en el primer acercamiento a este escenario y en las tres entrevistas a profundidad que en el periodo de noviembre de 2019 a abril de 2020 se realizaron.

El jardín de niños se encuentra en un suburbio de la zona periférica de la ciudad de Coatepec; cuenta con los servicios básicos: agua, luz, drenaje, así como telefonía e Internet. El edificio escolar alberga los turnos matutino y vespertino. El escenario que se describirá corresponde al turno vespertino, de sostenimiento federal, con un horario de atención a los niños de 14:00 a 17:00 horas. El personal académico está conformado por cuatro educadoras encargadas de un grupo, un apoyo técnico, personal del Centro de Atención Psicológica a la Educación Preescolar (CAPEP), ${ }^{5}$ un maestro de educación física y la directora efectiva.

5 El CAPEP brinda un servicio de educación especial que está a disposición de la comunidad para apoyar la atención escolar de alumnos con necesidades educativas especiales, contribuyendo en los procesos de integración educativa de estos en escuelas de educación inicial y básica. El CAPEP opera a partir del Programa de Fortalecimiento de la Educación Especial y la Integración Educativa (Diario Oficial de la Federación, 2006). 
Es un jardín de niños integrador, ${ }^{6}$ con un aumento significativo en la matrícula de niños y niñas con necesidades educativas especiales o discapacidades en los últimos ciclos escolares (EUM.EP1.27112019).

Las docentes que integran la plantilla tienen más de 20 años de servicio, una de ellas está a punto de jubilarse. La directora tiene más de 30 años de experiencia laboral como docente, pero en este cargo tiene diez (ED1.18092019).

En el ciclo escolar 2020-2021, la educadora participante de este estudio trabaja con un grupo multigrado, con una matrícula de 12 niños: 6 niños de primer grado con 3 años de edad y 6 niños de segundo grado con 4 años.

Las condiciones sociales, económicas y culturales de la comunidad educativa y del contexto inmediato se han visto afectadas por la delincuencia organizada que, en los últimos años, ha ido marcando la cotidianidad del entorno. El personal ha decidido tomar medidas preventivas para preservar su seguridad; una de ellas es salir todos juntos del establecimiento escolar.

En las inmediaciones del jardín de niños se destaca el comercio formal e informal. En relación con el acceso a la red, datos móviles y dispositivos para su uso, existe una cobertura menor a $50 \%$. Tan solo en el grupo escolar atendido por la educadora logra conectarse un promedio de 4 niñas de una matrícula de doce.

La información descrita permite visualizar un escenario que enmarca algunas condiciones desfavorables correspondientes a las características de los contextos marginales (INEE, 2010; Enríquez, 2011). Ante este escenario, interesa tratar de visibilizar, mediante los resultados de este estudio, cómo la acción docente evidencia una búsqueda de alternativas que provocan algunos procesos de cambio o de transformación ante las condiciones y expectativas de vida de las niñas y los niños preescolares atendidos (Redondo y Thisted, 1997).

\footnotetext{
${ }^{6}$ Los jardines de niños integradores son instituciones que se inscriben en el marco de la integración educativa, iniciada en México en 1992. De manera formal, las escuelas de educación básica se rigen a partir de 2002 por el Programa Nacional de Fortalecimiento de la educación especial y de la integración educativa, mismo que define la integración educativa como el "proceso por el cual los niños, las niñas y los jóvenes con necesidades educativas especiales asociadas con alguna discapacidad, con aptitudes sobresalientes o con otros factores, estudian en aulas y escuelas regulares, y reciben los apoyos necesarios para tener acceso a los propósitos generales de la educación" (SEP, 2002).
} 


\section{Fundamentación teórica}

\subsection{Saber docente}

El saber docente se ha estudiado, principalmente, a partir de las últimas dos décadas del siglo XX. Analizarlo desde distintas perspectivas ha posibilitado un mayor acercamiento y comprensión del profesorado al permitirles conocer cuáles han sido las causas que les hacen desenvolverse profesionalmente de la manera en que lo hacen durante sus intervenciones didácticas. Entre los aportes de los distintos autores que han estudiado el saber docente, interesa recuperar la postura de Tardif (2010), quien lo concibe como "un saber plural, formado por una amalgama, más o menos coherente, de saberes procedentes de la formación profesional y disciplinarios, curriculares y experienciales" (p. 29).

Se rescatan también las aportaciones de Mercado (2014), quien asume la conformación de los saberes docentes desde una construcción histórico-social, en donde, a través de la cotidianidad, se actúa ante cierta situación, según la propia historia y el contexto inmediato, pero sin olvidar que la propia historia incluye las interacciones sociales que el individuo ha logrado incorporar e identificar dentro de la tarea como enseñante. En consonancia con esto, se recupera el concepto de Contreras et al. (2017), quienes conciben los saberes docentes como estructuras mentales que se conforman a través de las interacciones del profesor en los distintos entornos en donde suele intervenir cotidianamente y que son manifestados al resolver problemas o al tomar decisiones durante la práctica.

Tardif (2010) conceptualiza los saberes profesionales como plurales y heterogéneos porque se generan a partir de distintas fuentes, las cuales se relacionan directamente con la historia de vida del docente y con su formación escolar. Los considera heterogéneos porque es difícil que el profesorado tenga conocimientos unificados o plantee su práctica desde una sola teoría. Este mismo autor reconoce una postura para solucionar el pluralismo epistemológico en la cual determina que el saber docente tiene un origen social, apegándose a los lugares en donde las y los docentes actúan, se forman o trabajan. Para él, el saber docente es solo aquel que puede ser declarado de manera consciente y argumentada. Lo asume situado y personalizado. En la tabla 1, se observan los tipos de saber y sus fuentes de origen, las cuales influyen en el desempeño del docente. 
Tabla 1.

Los saberes docentes y su origen

\section{Tipo de saber}

Saberes personales

Saberes procedentes de la formación escolar anterior

Saberes procedentes de la formación profesional para la docencia

Saberes procedentes de los planes y programas de estudio

Saberes procedentes de la propia experiencia en la profesión

Fuente: Adaptado de la Tabla 1. Los saberes de los docentes, por M. Tardif, 2010. Los saberes del docente y su desarrollo profesional, p. 48. Derechos reservados por Editora Vozes Ltda, Petrópolis, RJ (Brasil)

De las fuentes aquí expuestas se deriva la tipología y la caracterización de los saberes docentes: profesional, disciplinar, curricular y experiencial (Tardif, 2010). Esta tipología ha sido la base para algunas investigaciones que los han categorizado como: saberes de formación, experienciales, del profesor-investigador, del profesor reflexivo-cognitivo, reflexivo-social y educativo-crítico (Maris y Maciel, 2017).

Por otro lado, la heterogeneidad de los saberes profesionales parte del planteamiento de los propósitos y de los objetivos educativos, los cuales intentan atender el desarrollo de distintos tipos de conocimiento en diversos niveles. Tardif (2010) también categoriza las prácticas profesionales en heterónomas y heterogéneas, determinadas por las demandas de los propios grupos. Heterónomas desde el momento en que se decide cumplir con un propósito u objetivo educativo y heterogéneas cuando se atiende de manera específica e individual al alumnado que así lo requiera.

Para finalizar este apartado, interesa recuperar el concepto de saber docente planteado por Gaete (2011): el "conjunto de conocimientos, creencias y valores que guían las acciones y que se adquiriría en el contexto de una historia de vida y de una carrera profesional" (p. 17).

\subsection{El análisis de los saberes docentes desde los aportes de la didáctica profesional}

El análisis de las situaciones reales de trabajo es una propuesta que sugiere la didáctica profesional dentro del campo de la investigación, ya que permite enmarcar momentos específicos del desempeño de quien es observado, recursos invaluables y genuinos que

Los contenidos de este artículo están bajo una licencia Creative Commons 
aportan de manera significativa a la formación profesional ya sea inicial o continua. Para ello se sugiere acercamientos basados en la observación y sistematización objetiva con el apoyo de audio y videograbaciones (Vinatier, 2013).

En relación con el estudio que se reporta en este artículo, es importante recuperar las aportaciones metodológicas que este campo de investigación plantea, aún en las condiciones derivadas del confinamiento por la COVID-19. Hoy día, se viven con mayor frecuencia situaciones educativas mediadas por plataformas virtuales o por servicios de videoconferencias anclados en la nube que permiten reuniones virtuales, las cuales pueden ser grabadas con el propósito de recuperar lo que sucede, se dialoga, se comunica o se acuerda.

Bajo estas circunstancias, las sesiones mediadas por Zoom que, además de ser grabadas, fueron observadas y registradas por la investigadora son el insumo esencial para analizar las interacciones de la docente con el alumnado y detectar los saberes que emergen durante los procesos de enseñanza.

Los conceptos básicos que permiten una comprensión global de este campo de investigación son: esquema, actividad profesional en situación ${ }^{7}$ y experiencia (Vinatier, 2013). En la didáctica profesional, la interacción que se genera entre la persona y la realidad se conceptualiza como esquema, entendido este como el desempeño o la respuesta específica o ante un estímulo determinado. Es un proceso que atiende situaciones mediadas por la realidad, es reiterativo operativamente, y no debe confundirse con la conducta en sí.

Para la didáctica profesional, una situación es todo acto que sucede durante un evento específico, dado que se preocupa por comprender el quehacer docente en la toma de decisiones o en la búsqueda de estrategias para atender los intereses del estudiantado. Se sugiere elucidar entre las razones y problemas a los que se enfrenta el profesorado y las actividades analizadas a través de procesos reflexivos que doten de recursos para mejorar las prácticas. Para ello se propone el binomio formación profesional e investigación, como apoyo en la creación de nuevas formas de reflexión.

\footnotetext{
7 Hablar de actividad profesional en situación es referirse al momento preciso en que el profesional está actuando o interviniendo. Para la didáctica profesional no es necesario revisar los momentos previos a la acción: planeación, ni después de la acción: evaluación; por tanto, estos procesos no son analizados.
} 


\subsection{El papel de las interacciones dentro de la didáctica profesional}

Al analizar los procesos de enseñanza y aprendizaje, la didáctica profesional procura identificar los momentos de interacción cara a cara generados entre docente y alumnado, los cuales se determinan a través de los intercambios verbales mismos que permiten clasificarlos a partir de la influencia ejercida entre participantes o en los procesos de comunicación efectuados.

Las interacciones escolares dependen de los interlocutores presentes y de lo que hablan, son diálogos "prescritos por el docente y negociados por el estudiantado" (Vinatier, 2013, p. 51). Las negociaciones dependerán de los saberes de los interlocutores.

Este modelo de análisis recupera algunos principios de la etnografía de la comunicación y se interesa en recoger aspectos de carácter metodológico en el análisis de las conversaciones. Esta etnografía declara, en los actos de hablar y de comunicación interpersonal, una dimensión esencial para la construcción de la cultura, aspecto que, en este estudio, de manera específica, se traslada a la cultura construida por la educación a distancia, del tipo educación remota emergente.

Las contribuciones teóricas anteriores le permiten a Vinatier (2013) conformar el Modelo E-P-R, concebido como un dispositivo de coexplicitación para conceptualizar la experiencia, y que analiza la actividad profesional en situación, bajo reflexiones colectivas que permitan el establecimiento de colegiados entre investigadores y profesionales, docentes en este caso particular.

El Modelo E-P-R es un modelo de análisis de la profesión y, en el caso de la educación, pone en el centro al profesorado para que analice sus propias prácticas en colaboración con sus pares. Representa un juego dialógico entre las dimensiones individual y colegiada. Implica procesos de investigación formativa que toma en consideración los conocimientos y saberes que se generan dentro de los distintos momentos en una clase. Para el análisis, propone tres polos vinculados entre sí, los que a su vez están en tensión constante: polos epistemológico, pragmático y relacional.

Como metodología propone la observación de la intervención en momentos específicos de la actividad docente, la cual debe acompañarse de video o de audiograbaciones; debe ser transcrita y debe realizarse un análisis conceptual en colectivo de lo transcrito. Vinatier (2013) sugiere un contraste entre la información transcrita y ejemplos específicos elaborados que permitan reforzar aquello que se está analizando. 
Para ampliar el planteamiento metodológico de este modelo, se considera necesario recuperar las cuatro etapas por las que funcionan los dispositivos de coexplicitación (Vinatier, 2013, pp. 77-78):

A. Contrato de comunicación entre participantes.

B. Registro de observación y transcripción realizadas por la o el docente, con momentos específicos que se consideren problemáticos dentro de sus clases.

C. Análisis de las interacciones escolares desarrolladas por quien observa, puestos a disposición del o la docente; se basa en poner en tensión los tres polos.

D. Los análisis elaborados se discuten en colectivo con la intención de que el profesorado se apropie de aquello que se analiza y haga un balance y autoevaluación de su propio desempeño, buscando fomentar su autonomía, al hacerse responsable de la toma de decisiones in situ que le permitan hacer cambios para transformar su docencia.

De manera específica, se hará uso del Modelo E-P-R como estrategia mediadora que permita dar cuenta de las implicaciones que tienen los saberes docentes en los procesos de enseñanza durante la pandemia, a través del análisis de las tensiones existentes entre el polo epistemológico, el pragmático y el relacional.

Para tener mayor claridad de lo que son cada uno de los polos que conforman el Modelo E-P-R, se recurre a los planteamientos de Fierro y Fortoul (2017), quienes están fundamentadas en Vinatier (2013).

- El polo pragmático es el conjunto de tareas de orden didáctico que comprometen las actuaciones entre docentes y estudiantes con la intención de desarrollar u obtener aprendizajes. Son acciones secuenciadas y consideradas, principalmente por el o la docente, como las más adecuadas para conseguir los fines educativos planteados.

- El polo relacional se refiere a las dinámicas intersubjetivas que se generan dentro de los actores. Puede ser una causa para que se tense el quehacer pedagógico dado el tipo de relaciones interpersonales que se observan entre docente-alumnado y entre pares. Aquí se pueden observar los roles asumidos y permitidos, el nivel de implicación y los tipos de recursos lingüísticos y no verbales utilizados.

- El polo epistemológico tiene que ver con la manera concreta en que el estudiantado construye saberes, para lo cual se hace referencia a las distintas figuras del aprendizaje como proceso o como producto. 
Para efectos de este estudio, se hicieron algunas modificaciones al planteamiento metodológico de origen (Vinatier, 2013). La primera modificación es en relación con el punto B del dispositivo de coexplicitación, ya que fue la investigadora quien hizo los registros y transcripciones. En relación con el inciso $D$, los análisis elaborados a la fecha se han discutido solo entre educadora e investigadora. La puesta en común entre pares se hará a inicios del ciclo escolar 2021-2022. Cabe precisar que, si bien en este estudio no hay intercambios verbales cara a cara, el análisis se centra en los diálogos entre la docente y su alumnado a partir de la observación sincrónica de las sesiones mediadas por Zoom, las cuales además fueron grabadas para poder acudir a ellas en los momentos de análisis.

\subsection{Educación remota, mediaciones pedagógicas y enseñanza situada}

En respuesta a las condiciones a las cuales se ha tenido que transitar como resultado del confinamiento ocasionado por el SARS-CoV-2, merced a las cuales la educación, de pronto, se vio impedida para ser presencial y hubo de tornarse en una de naturaleza remota (Loayza-Maturrano, 2020), hoy día la "nueva normalidad" es, en efecto, la no presencialidad entre docentes y educandos (Alcántara, 2020). El personal docente y directivo del jardín de niños en el que se encuentra adscrita la educadora participante de este estudio ha buscado algunas opciones y estrategias para seguir brindando educación a los niños y las niñas matriculados. Los acuerdos fueron pedir a los padres y las madres de familia seguir la programación "Aprende en casa" para atender los contenidos del nivel en que sus hijos están inscritos. Después de realizar una encuesta para valorar la pertinencia de realizar reuniones mediadas por los servicios de Google Meet o de Zoom, decidieron que harían sesiones por Zoom, los lunes y los jueves, con un horario de 16:00 a 16:40 horas.

Ante la emergencia, esta institución educativa, como muchas otras, cayó en un modelo de educación a distancia incipiente (Loayza-Maturrano, 2020), utilizando la educación remota, entendida como un sistema de educación sostenido en las Tecnologías de la Información y la Comunicación (TIC), tales como la Internet, la telefonía móvil, la televisión o la radio, con el propósito de potenciar los sistemas educativos (Pastrán, Gil y Cervantes, 2020; Gil, 2019). Cabe resaltar que este tipo de educación ha sido utilizada desde hace varios años; sin embargo, hoy día su uso se ha potencializado por el acontecimiento de la pandemia.

En función de este tipo de educación y de los alcances y problemas que ha implicado tratar de llevarla a cabo, en los microescenarios tales como las escuelas y las aulas es necesario hablar de las mediaciones pedagógicas que los docentes han debido crear, 
transitando de la mediación de tipo presencial a tratar de confiar en los recursos digitales y comunicativos, presentados como materiales para el aprendizaje que le permiten al alumnado concretar el sentido del proceso educativo (Malagón, 2009).

En el entendido de que la mediación pedagógica es "el tratamiento de contenidos y de las formas de expresión de los diferentes temas a fin de hacer posible el acto educativo, dentro del horizonte de una educación concebida como participación, creatividad, expresividad y relacionalidad (Gutiérrez y Prieto, 1999, p. 9), interesa reportar las principales mediaciones que se vislumbran en el actuar de la educadora participante de este estudio, partiendo de la idea de que todo acto educativo está mediado por la pedagogía y va más allá de un sistema de enseñanza basado en la transmisión de información, concepción esta última que suele preponderar en algunos sistemas instruccionales (Malagón, 2009).

En relación con el aprendizaje situado, es importante considerar que va íntimamente relacionado con la enseñanza de este tipo. Algunos autores sostienen que el conocimiento es situado porque es parte y producto del contexto, la cultura y la actividad que se está desarrollando; por lo tanto, el aprendizaje situado debe ser un proceso multidimensional, de apropiación de la cultura, que involucra el pensamiento, la afectividad y la acción. En este enfoque, el papel del docente es el de proveer las actividades y el contexto pertinente para que el estudiantado lo aproveche y aprenda (Díaz-Barriga, 2006).

\section{Metodología}

La investigación se sitúa en el paradigma cualitativo, dado que permite conocer, interpretar, comprender y analizar los saberes docentes que se generan a partir de las prácticas de enseñanza observadas dentro un contexto escolar ubicado en un escenario urbano-marginado.

\subsection{Enfoque}

Este trabajo tiene un alcance de carácter descriptivo porque evidencia los saberes docentes declarados por la educadora en las entrevistas a profundidad y los emergidos durante las intervenciones mediadas por la tecnología y situadas en las características del contexto marginal donde se desempeña. Trata asimismo de interpretar el alcance de estos saberes en el tipo de mediaciones y estrategias que diseña para promover procesos de aprendizaje en el alumnado que, durante el ciclo escolar 2020-2021, es atendido. 


\subsection{Unidades de análisis}

Para comprender la emergencia de los saberes docentes hasta lograr tipificarlos, se consideró pertinente utilizar el estudio de casos referido por Yin (1994) como

... la investigación que trata de manera exitosa con una situación que se distingue técnicamente, contando con muchas más variables que datos observacionales; y, como resultado, se basa en múltiples fuentes de evidencia, con datos que deben converger en un estilo de triangulación; y, también como resultado, se beneficia del desarrollo previo de proposiciones teóricas que guían la recolección y el análisis de datos. (p. 13)

Los criterios de selección se basaron en la experiencia docente: al menos 7 años frente a grupo y una trayectoria reconocida por la comunidad educativa. La elección fue en atención a ambos criterios y a las características del jardín de niños y el contexto donde se desempeña. El seguimiento a la educadora se llevó a cabo mediante consentimiento informado, bajo la autorización de su supervisora escolar y de la directora del jardín de niños donde labora. El primer acercamiento se efectuó el 18 de septiembre de 2019, a través de un oficio donde se explicitaba brevemente el objetivo y la metodología de la investigación. Después se realizaron tres entrevistas a profundidad en las siguientes fechas: el 27 de noviembre de 2019; el 19 de enero y el 25 de abril de 2020, las cuales permitieron caracterizar a la educadora.

Como unidades de análisis se declaran los saberes docentes, las mediaciones pedagógicas y la influencia de las condiciones contextuales en los saberes docentes.

\subsubsection{Participantes}

La educadora es licenciada en educación preescolar, egresada de la Normal Veracruzana, formada con el Plan de Estudios 1984. Tiene 20 años de servicio. Ha sido docente frente a grupo en escuelas unitarias y bidocentes, directora y apoyo técnico escolar y de supervisión. Fue coordinadora de un programa de Ciencias en la Secretaría de Educación de Veracruz durante 10 años. En el turno matutino, es docente de la licenciatura en Educación Preescolar y jefa de un área de la subdirección de docencia en la escuela normal donde fue formada. También es docente en un jardín de niños vespertino urbano-marginado de organización completa y de sostenimiento federal, ubicado en la zona periférica de la ciudad de Coatepec, Veracruz. 


\subsection{Técnicas de recolección}

La observación, durante la contingencia sanitaria por la COVID-19, se sistematizó en registros descriptivos en un cuaderno de notas de campo con apoyo de un formato (Bertely, 2000). Tales registros fueron complementados con apoyos tecnológicos, específicamente audio y videograbaciones, tal como lo sugiere la didáctica profesional (Vinatier, 2013).

Durante la primera fase de la investigación se llevaron a cabo entrevistas a profundidad. Esta técnica fue fundamental porque permitió complementar la información derivada de la observación directa. El guion inicial de las entrevistas a profundidad planteaba cuestionamientos que permitieron conocer, desde la voz de la educadora, cómo es que esta concibe los saberes docentes, cuáles son aquellos en los que sitúa o justifica su labor.

Las entrevistas también permitieron conocer un poco más sobre su vida personal, cómo ha sido formada, cuál ha sido su experiencia como alumna, cuáles han sido las principales influencias sociales e históricas en su manera de concebir la docencia, la educación preescolar, el niño preescolar y los procesos de planeación, intervención y evaluación, así como datos generales sobre dónde vive y acerca de su formación inicial y continua.

Esta técnica fue reforzada por algunas entrevistas semiestructuradas, a fin de ahondar en el reconocimiento de acciones, con el ánimo de comprender eso que la docente dice hacer, conocer cómo lo hace y reconocer, en colaboración con ella, por qué lo hizo, en esa interacción pragmática entre lo Emic y lo Epic (Dietz, 2017). La última entrevista se realizó el 25 de marzo; en esta se rescataron aspectos referentes a la experiencia que le ha representado el trabajo remoto a distancia (Díaz-Barriga, 2021; comunicación personal, 20 de marzo de 2021). En la tabla 2 se presentan las técnicas, los instrumentos y las nomenclaturas de modo que puedan ser identificadas fácilmente en el apartado referente al análisis de resultados. En la última columna se enuncia el procedimiento, brevemente explicitado. 
Tabla 2.

\begin{tabular}{|c|c|c|}
\hline \multicolumn{2}{|r|}{ Instrumento y } & Proc \\
\hline $\begin{array}{l}\text { Entrevista } \\
\text { profundidad }\end{array}$ & $\begin{array}{l}\text { Guion de entrevista con } \\
\text { la tipología de Tardif } \\
\text { (2010) } \\
\text { 1. EUM.EP1.27112019 } \\
\text { Duración: 1:03'35 } \\
\text { 2. EUM.EP2.19012020 } \\
\text { Duración: 0:57'46 } \\
\text { 3. EUM.EP3.25042020 } \\
\text { Duración: } 1: 50^{\prime} 03\end{array}$ & $\begin{array}{l}\text { Instrumento diseñado para ser aplicado al inicio de la } \\
\text { investigación, con el siguiente objetivo: } \\
\text { - Indagar a partir de los cuestionamientos cuáles eran los } \\
\text { saberes docentes desde la tipología de Tardif (2010), } \\
\text { para cruzar los datos declarados con los observados. } \\
\text { Se llevó a cabo en tres momentos. El saber experiencial } \\
\text { abarcó los dos primeros. }\end{array}$ \\
\hline \multirow[t]{3}{*}{$\begin{array}{l}\text { Entrevista } \\
\text { semiestructurada }\end{array}$} & $\begin{array}{l}\text { Guion de entrevista para } \\
\text { la directora del plantel } \\
\text { ED1.18092019 }\end{array}$ & $\begin{array}{l}\text { Se aplicó en el primer acercamiento y con la intención de } \\
\text { conocer la organización escolar y algunas de las opinions } \\
\text { de la educadora sobre la intervención docente del caso } \\
\text { estudiado. }\end{array}$ \\
\hline & $\begin{array}{l}\text { Guion de entrevista para } \\
\text { análisis de resultados. } \\
\text { Saberes declarados } \\
\text { EUM.ESemi } 1.02092020\end{array}$ & $\begin{array}{l}\text { Esta técnica se empleó para dar seguimiento a los distintos } \\
\text { cortes de la investigación: análisis de la intervención con la } \\
\text { educadora. }\end{array}$ \\
\hline & $\begin{array}{l}\text { Guion de entrevista para } \\
\text { análisis de resultados. } \\
\text { EUM.ESemi2.25032021 }\end{array}$ & $\begin{array}{l}\text { - La primera entrevista se realizó el } 2 \text { de septiembre de } \\
2020 \text {. } \\
\text { - La segunda entrevista se realizó el } 25 \text { de marzo de } 2021 \text {. }\end{array}$ \\
\hline Observación & $\begin{array}{l}\text { Guion de observación } \\
\text { Cuaderno de notas } \\
\text { 1. EUM.Obs. } 28092020 \\
\text { 2. EUM.Obs. } 05102020 \\
\text { 3. EUM.Obs.09112020 } \\
\text { 4. EUM.Obs. } 14122020 \\
\text { 5. EUM.Obs. } 25012021 \\
\text { 6. EUM.Obs. } 08022021 \\
\text { 7. EUM.Obs. } 15022021 \\
\text { 8. EUM.Obs. } 22022021\end{array}$ & $\begin{array}{l}\text { - Guion de observación: Este instrumento se utilizó para el } \\
\text { reconocimiento de la institución educativa y el contexto } \\
\text { inmediato en el primer acercamiento. } \\
\text { - Cuaderno de notas: Se elaboró bajo las siguientes } \\
\text { categorías de observación: } \\
\text { a. Nombre de la actividad. } \\
\text { b. Descripción de la actividad, frases de la educadora o } \\
\text { alumnas. Evidencias de los procesos de enseñanza o } \\
\text { aprendizaje o polos de tensión: epistemológico, pragmático } \\
\text { o relacional. } \\
\text { c. Comentarios o reflexiones de la investigadora }\end{array}$ \\
\hline
\end{tabular}

Nomenclaturas: De izquierda a derecha, enuncian las iniciales de la modalidad educativa donde labora la educadora (EUM- Educadora Urbano Marginada). Iniciales del instrumento o técnica utilizado, número secuenciado de la técnica aplicada (entrevista u observación) y fecha de realización. También se señala el tiempo en horas, minutos y segundos que duró cada una de las entrevistas.

Fuente: Elaboración propia (2021).

\subsection{Procesamiento de análisis}

La forma en que se ha abordado el fenómeno tiene como propósito la reconstrucción de la realidad que se vive en un escenario mediado por la tecnología -traducido en clases remotas-, para identificar el papel que juegan los saberes docentes durante los procesos de enseñanza y sus implicaciones en los procesos de aprendizaje. 
El primer acercamiento fue una fase exploratoria mediante la cual se obtuvo información acerca del escenario escolar, la comunidad inmediata y algunos padres y madres de los niños o familiares de estos. Se entrevistó a la directora del plantel, dándole a conocer los objetivos de la investigación y ofreciéndole una breve explicación sobre la estrategia metodológica y la relevancia del estudio, además de subrayar el compromiso de presentarles un informe acerca de los resultados antes de su difusión. Esto en el marco del código de ética de la investigación, fundamentado en los principios de preservación de la identidad y la protección de datos.

Este acercamiento permitió conocer de manera general lo que sucede en el lugar de trabajo, ciertos aspectos sobre las dinámicas organizacionales, la estructura y las condiciones físicas de la institución, además de aguzar la percepción sobre el desempeño de la docente, la cual tiene, cabe señalarlo, el reconocimiento explícito de la directora. La información obtenida permitió afinar la ruta metodológica a seguir.

En reconocimiento a las aportaciones de la didáctica profesional, se recuperaron las fases de los dispositivos de coexplicitación: 1. Contrato de comunicación entre la investigadora y la educadora. 2. Registro de la actividad observada en un cuaderno de notas, bajo un formato que incluye tres columnas (Bertely, 2000): en la primera se registra el nombre de la actividad; en la segunda se describe la actividad observada mediada por la plataforma Zoom. Como respaldo de dicha descripción se grabó cada una de las sesiones para tener la posibilidad de acudir a ellas en el caso de querer rescatar algún diálogo, gesto o comunicación no verbal, o ante el requerimiento de traer a la memoria el escenario que media los ambientes de aprendizaje. En la tercera columna se registran comentarios, preguntas, dudas o reflexiones que permiten hacer el análisis y dialogar con la educadora al respecto.

En total, se logró observar a la educadora durante ocho sesiones dentro del ciclo escolar 2020-2021. Hubo una entrevista semiestructurada llevada a cabo el 2 de septiembre de 2020, que permitió conocer los acuerdos generales con madres y padres de familia, derivados de una reunión que sostuvieron a finales del mes de agosto, en la cual se discutieron aspectos esenciales para la toma de clases remotas. También se analizaron los resultados de los saberes declarados en las entrevistas a profundidad (ESemi1.02092020). El 22 de febrero de 2021 se llevó a cabo la última observación.

El Modelo E-P-R sirvió como estrategia mediadora para reconocer, a partir de las tensiones desarrolladas en los tres polos, cómo los saberes docentes influyen en los procesos de enseñanza mediada por la tecnología. Los análisis elaborados fueron discutidos con la docente con la intención de plantear estrategias de mejora en sus intervenciones, respetando 
el objetivo primordial de la didáctica profesional (Vinatier, 2013). Tal intercambio se llevó a cabo a través de una entrevista semiestructurada efectuada el 25 de marzo de 2021 (ESemi.25032021).

\section{Resultados}

En respuesta a la propuesta metodológica que parte de una perspectiva cualitativa interpretativa, se ha pretendido comprender, desde la individualidad del caso estudiado, la manera en que la educadora se desenvuelve y cómo sus saberes le hacen ser y hacer docencia (Tardif, 2010), destacando las mediaciones creadas en relación con las demandas derivadas de la contingencia sanitaria iniciada en marzo de 2020 y bajo las condiciones del contexto en el que viven sus alumnas y alumnos.

\subsection{Los saberes que configuran el "ser" docente}

El reconocimiento de los saberes docentes bajo la conceptualización propuesta por Tardif (2010) permite descubrir a una profesional de la educación consciente de lo que hace y capaz de argumentar por qué lo hace. Para tal efecto interesa seguir caracterizando el caso analizado, de tal forma que la información recuperada en las diferentes fuentes permita contrastar datos que den respuesta a las preguntas de investigación. En este apartado interesa destacar la visualización a la que alude este autor cuando refiere que el saber docente se ubica entre el ser y el hacer de todo profesional de la educación.

\subsubsection{Saberes personales, escolares, curriculares y profesionales}

En la tercera entrevista a profundidad, la educadora narra sucesos relativos a su vida personal y expresó aspectos de su formación escolar que le hicieron tomar decisiones en cuanto a sus estudios para ser docente. Por ejemplo, el acoso que sufrió por parte de una compañera durante su educación preescolar. La niña le pegaba y la agredida nunca se defendió ni se lo comentó a su familia, situación que le resulta extraña, porque la comunicación de este tipo de hechos es algo que la docente busca promover en el alumnado.

Como estudiante de educación superior, la educadora enfrentó dos sucesos que marcaron su vida. El primero fue un accidente que sufrió mientras cursaba el primer semestre de la licenciatura en educación preescolar en una Escuela Normal. En una de sus clases se cayó y se golpeó la cabeza, quedando en coma por más de un mes. Para recuperarse del posible daño cognitivo generado por el accidente, el médico le recomendó estudiar música, 
por lo que la convaleciente se inscribió en la facultad de música y aprendió a tocar el violín a la par que estudiaba en la Normal. Recuerda que la empatía y apoyo brindados por el director de la Escuela Normal, los compañeros y los catedráticos fueron condiciones que le permitieron llevar a término su formación inicial como docente (EUM.EP3.25042020). El segundo suceso fue una enfermedad que dejó incapacitado a su papá, lo que le implicó abandonar sus estudios de música y vender su instrumento para apoyar con los gastos del hogar.

Un saber curricular que se resalta en la entrevista es la manera en que la docente asume las diversas reformas educativas del nivel preescolar que le ha tocado vivir (SEP, 1992; SEP, 2004; SEP, 2011; SEP, 2017). Ella expresa: "Aunque parezca un discurso muy gastado, es necesario que los cambios surjan del propio docente, para que realmente exista una transformación" (EUM.EP3.25042020).

La maternidad es una experiencia que ha marcado su vida. Ella la asume como un punto clave o crucial para su quehacer docente. Fue una docente antes y otra después de ser mamá, aunque no desarrolla una explicación al respecto (EUM.EP1.27112019).

Un aspecto reiterativo dentro de su discurso es la importancia que le da a la educación preescolar, reconociéndola como un servicio social y asumiéndose parte de una comunidad educativa. Formar a la niñez preescolar es una gran responsabilidad, "es una tarea compartida con las madres y padres de familia, pero que tiene mucho peso al ser educación formal" (EUM.EP1.27112019). Tales declaraciones son congruentes con sus intervenciones mediadas por la tecnología, ya que diseña actividades basadas en el aprendizaje situado: parte de las necesidades de las niñas y los niños del grupo, recupera conocimientos previos y adecua aspectos relativos a sus contextos, como en la actividad diseñada para la identificación de numerales. Los niños investigaron su dirección, la escriben, después le explican a la docente por dónde viven y ella hace hincapié en el nombre de la calle y en el número de su casa (EUM.Obs.05102020).

\subsubsection{Saberes experienciales y factores contextuales}

El trabajo como docente de la licenciatura en educación preescolar en una escuela normal es un saber experiencial que le ha permitido a la maestra ser un modelo formativo para las futuras docentes, ${ }^{8}$ debido a que algunas de estas han ido a observarla en sus funciones como educadora. Esta situación también le ha significado una gran responsabilidad, al mostrar

\footnotetext{
${ }^{8}$ Se habla en femenino porque, en la escuela normal en la que la docente labora, $99 \%$ del estudiantado son mujeres. 
la congruencia y el equilibrio que debe haber entre lo que se enseña y lo que se hace, entre el deber ser y el ser (EUM.EP1.27112019).

Cabe destacar que su discurso y su actuar reflejan la preocupación que ella tiene por el alumnado. Como docente ha vivido situaciones complicadas de abuso a menores en algunos de los niños o las niñas, casos que a veces no ha sabido cómo atender y que le han permitido darse cuenta de lo vulnerables que muchas veces pueden llegar a ser los infantes, incluso ante sus propias familias.

La preocupación aquí descrita es una evidencia que la define como una docente heterogénea, considerando los tipos de práctica propuestos por Tardif (2010). La docente se manifiesta consciente de las necesidades individuales y en disposición para seguir aprendiendo cómo atender los requerimientos específicos de cada alumno o alumna.

Un incidente que destaca en su vida laboral es el que está viviendo actualmente: nunca había laborado en su localidad natal, hasta ahora. Su centro de trabajo se ubica a unas cuantas cuadras de su casa, pero el entorno en donde se encuentra la escuela le ha mostrado una ciudad que ella desconocía, un lugar que está dominado por la delincuencia organizada, donde ha habido muertes y balaceras. Los mismos padres o madres de familia les han dicho que, por ser docentes, cuentan con protección.

Un saber experiencial que se destaca es aquel en donde la maestra reconoce la estigmatización de la escuela vespertina; habla de comentarios que hacen algunos pobladores, incluso colegas, que juzgan o etiquetan al alumnado como estudiantes incapaces de hacer ciertas cosas, como acceder al turno matutino. Una idea que expresa y que permite identificarla bajo la visión de la educación y su poder de cambio (Redondo y Thisted, 1997) es la siguiente: "Los compañeros y compañeras que formamos parte de este jardín luchamos, luchamos sobre esta estigmatización que se tiene sobre las escuelas vespertinas, pues se dice que son escuelas para pobres, son escuelas para estudiantes que van mal en otras escuelas, son escuelas para papás que nunca pueden estar" (EUM.EP1.27112019).

Es interesante cómo la docente, al recuperar las ideas planteadas por un grupo social que juzga a estas escuelas, logra evidenciar en el colectivo docente del lugar donde trabaja una ideología de cambio, buscando la apreciación de un habitus desde lo que Bourdieu declara en relación con las estructuras sociales y el impacto de estas. Con respecto a esta idea, se observa congruencia, porque se detecta cohesión en el equipo docente, traducida en colaboración constante, ya que en tres de las sesiones observadas se logró observar participaciones del equipo de CAPEP, ya sea de la terapeuta de lenguaje o del psicólogo. 
Para finalizar este apartado, es necesario hacer hincapié en aquellos saberes que se han ido conformando a partir de la historia de vida, en la cual confluyen aquellas fuentes del saber que menciona Tardif (2010), experiencias personales que le han marcado en su "ser docente" y en su "hacer docencia".

Hoy día ella está preocupada por evitar el acoso escolar, por ser empática y propositiva con su alumnado, por buscar estrategias en colectivo para acabar con la estigmatización de un tipo de escuela, por ser modelo para las futuras educadoras, por tratar de explicarse cómo un contexto tan cercano a su hogar puede ofrecer tanta violencia, miedo e indefensión, lo cual remite a la historicidad y a aspectos sociales que van marcando las trayectorias e identidades docentes que van recreando el saber, tal como lo concibe Mercado (2014) desde esa construcción social que parte de la cotidianidad, considerada la génesis del saber docente.

\subsection{Intervención docente: saberes, reflexiones y mediaciones derivadas de la pandemia}

Para detectar los polos de tensión que determinan la intervención docente (Vinatier, 2013) y los saberes docentes que motivan dicha tensión, se considera necesario partir de la determinación de los esquemas que guían la intervención de la docente observada.

El primer esquema es el de la presencialidad, considerado dentro de esta categoría porque la docente lo refiere como el principal reto generado por la pandemia. Entonces, al enunciarlo, se asume como una interacción esencial para ella en su quehacer docente y en el recorrido emergente a la no presencialidad. Este esquema "se rompió de golpe". Transitar de la presencialidad a la no presencialidad le ha solicitado estar en la búsqueda creativa de actividades. Otro de los esquemas que caracteriza su quehacer docente es la enseñanza situada. Para comprender mejor cada uno de estos esquemas, se presentarán a continuación algunas de las interacciones que los evidencian, las cuales, además, resaltan algunos saberes docentes que estas originan y las mediaciones que las soportan o contienen.

\subsubsection{Presencialidad vs. no presencialidad}

La enseñanza remota mediada por Zoom ha significado para la docente todo un reto. Ella confiesa que el día en que realizó la primera sesión fue "como en el primer día de su servicio docente" (ESemi1.02092020): "Preparar la sesión me hizo imaginar que iba a salir en la televisión, sentía que mucha gente me iba a ver; incluso hice un escenario para que los niños creyeran que era su aula, el cual fui cambiando o modificando, pero en realidad no les importó mucho" (ESemi2.25032021). 
En la entrevista semiestructurada llevada a cabo el 2 de septiembre, la educadora dio a conocer algunos acuerdos tomados con las madres y padres de familia del grupo atendido y con el equipo docente y directivo del jardín de niños, quienes sugirieron que las sesiones mediadas por Zoom se realizarían los lunes y los jueves con un horario de 16:00 a 16:40 horas. También acordaron que el alumnado que asiste a esta institución educativa tendría que ver los programas de la estrategia nacional "Aprende en casa". Tal acuerdo es algo que no le agrada, pero lo asume como una estrategia emergente (ESemi1.02092020).

Para ella ha sido un desafío "crear un concepto de escuela", porque algunos de sus alumnos o alumnas están viviendo su primera experiencia escolar. "La idea que tienen de escuela es totalmente distinta a la que experimentan dentro de la virtualidad". Declara que "una niña lloró el primer día de clases porque su mamá le había dicho que iba a ir a la escuela, que conocería nuevos amigos, le compró una mochila y se ponía el uniforme de su hermano. Pero al darse cuenta de que la escuela era en una pantalla, esa idea no le gustó y entonces se puso a llorar porque ella quería ir a la escuela..." (ESemi2.25032021).

La docente comenta que quiere estar cercana a su alumnado en la medida de lo posible, sobre todo porque en este ciclo escolar ella es el primer contacto que la mayoría tiene con la educación; y el hecho de que sea a distancia les puede ser impactante. Este comentario evidencia la tensión del polo relacional sobre el pragmático y el epistemológico (Vinatier, 2013; Fierro y Fortoul, 2017).

\subsubsection{La enseñanza situada}

Las estrategias diseñadas conllevan como principio de intervención una postura perfilada hacia la enseñanza situada (Díaz-Barriga, 2006), estrategias que toman en cuenta la temporalidad y la duración de cada sesión considerando la edad del alumnado y sus lapsos de atención, que generalmente son cortos en los preescolares de 3 y 4 años de edad. En atención a esta característica, las ocho sesiones observadas tuvieron una duración máxima de 40 minutos. Cabe resaltar que para la educadora era muy importante ser puntual, tanto al inicio de la sesión como al cierre de esta, porque, con el paso de los meses, el colectivo docente decidió que las clases se efectuarían únicamente una vez por semana. La jornada tenía un horario de 14:00 a 16:40 horas; iniciaba con la sesión de educación física, seguida de arte o cantos y juegos; después se daba alguna terapia de lenguaje y se culminaba con su participación. La docente reconoce que las sesiones son muy largas, sobre todo para ser presenciadas desde la virtualidad. 
Este esquema destaca saberes profesionales y experienciales, en donde se observa el conocimiento científico y real del niño preescolar en función de sus periodos cortos de atención, y refleja a la maestra como una docente empática y con experiencia frente a grupo, ya que sabe o anticipa algunas reacciones en función del interactuar con los niños y las niñas en estas edades.

Las interacciones, aún mediadas por la tecnología, evidencian diálogos cercanos, gestos de interés, preguntas directas a las niñas que asisten; escucha atenta a lo que comentan y muestra empatía en el caso de que las frases emitidas no sean comprensibles, como en el caso de una de las niñas, quien, durante las primeras sesiones del ciclo escolar, manifestaba un nivel de lenguaje oral -su dicción- que lo mostraba casi ininteligible.

Una actividad que evidencia la enseñanza situada es la secuencia que llevó al alumnado a elaborar una carta para celebrar el día del amor y la amistad, la cual fue enviada a sus destinatarios el 14 de febrero. Un día después, la educadora describió cómo se sintieron los compañeros que la recibieron (EUM.Obs.15022021). Tal es una enseñanza situada, dado que recupera la cultura del contexto en donde se están desarrollando. Por otro lado, y en atención a lo que Díaz-Barriga (2006) reconoce como aprendizaje situado, esta secuencia didáctica fue un proceso multidimensional de apropiación cultural, que le implicó al alumnado el uso de su pensamiento, su afectividad y su actuar.

En la actividad observada dentro de la cual realizan un experimento, el 15 de febrero de 2021, la docente parte de la exposición de un problema, derivado de una experiencia propia. En esa ocasión les narró: "Ayer, al lavar los platos de mi casa, mi anillo se resbaló de mi dedo por el agua jabonosa y se hundió; tuve que buscar cómo sacarlo del tanque con agua". A continuación, les cuestiona si saben por qué el anillo se fue al fondo del tanque. Las niñas expresan sus hipótesis; dicen: "Es pesado, por eso se hundió" (EUM.Obs.15022021). Esto evidencia algunos de sus conocimientos previos; la docente los recupera para dar seguimiento a la actividad. De esta forma se puede apreciar cómo en el diálogo docente-alumna se van constituyendo algunos acuerdos tácitos que permiten una secuencia didáctica centrada en la resolución de problemas. En este diálogo se aprecia el manejo del polo epistemológico.

Las sesiones observadas, además de los diálogos docente-alumna, muestran algunos soliloquios que la docente establece al reparar en el manejo de su discurso, para cambiar algunos términos y volver a explicar algunas ideas que, después de decirlas, considera no fueron precisas. Este tipo de acciones evidencian a una docente consciente de su hacer, consciente de lo que dice y de cómo lo dice, al grado de que, durante la acción, es capaz de 
rectificar aquello que comunica, porque es consciente del impacto del lenguaje modelado por el adulto en la adquisición y el desarrollo del lenguaje en el niño preescolar, lo que muestra un polo epistemológico en tensión.

\subsubsection{Mediaciones principales}

En atención al concepto de mediación pedagógica en el que se basa este estudio, el cual resalta el tratamiento de contenidos y de las formas de expresión en el manejo de los diferentes temas (Gutiérrez y Prieto, 1999), se advierte que las mediaciones observadas y recurrentes dentro de las intervenciones fueron el uso del lenguaje oral y escrito, como recurso transversal, el uso del cuento para recuperar contenidos, el uso del juego como estrategia de aprendizaje y la empatía mostrada hacia el alumnado.

La educadora, aún a la distancia, muestra una capacidad para generar ambientes de aprendizaje fundados en la confianza, lo cual logra a través de un lenguaje oral y corporal que motiva a las alumnas al diálogo y a la participación continua; conforma diálogos basados en cuestionamientos para estimularlas a dar su opinión; expresa experiencias propias para situarlas en el tema a abordar; precisa términos o conceptos para ir ampliando el vocabulario de quien la escucha.

Otra mediación observada fue el uso del lenguaje escrito como apoyo en varias actividades, como el registro de asistencia, el cual está a la vista. La forma del registro va cambiando para atraer la atención de las niñas y, en algunos momentos, conocer sus estados de ánimo. Les solicita que comenten cómo se sienten o qué hicieron el día anterior. Una vez que las infantes comparten lo que les solicita, ella misma registra la asistencia, siempre haciendo alusión al nombre escrito de cada una de las alumnas. Esta acción se asienta como un saber docente que apoya las actividades de rutina esenciales dentro de los contenidos programáticos del nivel, ya que ayuda a dar estructura al pensamiento y a las acciones de los preescolares. Para recrear el ambiente, la docente utiliza algunas imágenes y frases cortas, que coloca en una pared que es captada por la cámara, a las que hace alusión leyéndolas, según sea el tema a abordar. Con esta acción recupera la funcionalidad de la lectura.

El uso del cuento como estrategia para recuperar los contenidos o aprendizajes esperados fue otra mediación recurrente. Una evidencia es el cuento "Cuenta ratones", con el cual, además de acercarlos a la lectura, utilizando estrategias como mostrarles la portada, decirles el nombre del autor, señalar el texto e ir marcando con el dedo la direccionalidad de la lectura, recupera contenidos del campo formativo de pensamiento matemático (SEP, 2017). 
En este caso, la maestra trabajó secuencia numérica al ir contando el número de ratones e ir sumando uno a uno. La manera de narrar los cuentos fue cambiando; por tanto, en esta mediación utilizó cuentos digitales y físicos; a veces les mostraba las imágenes o les cuestionaba para que anticiparan algunos sucesos. Otras veces les ponía un video, en donde una voz narraba la historia y las imágenes representativas iban exponiéndose en diapositivas. Con los cuentos elegidos reforzaba, además del acercamiento a la lectura y la escritura, algunos temas específicos.

La mediación principal para atender los procesos de aprendizaje del alumnado, y que evidencia la enseñanza situada, es la postura que asume y que le hace reconocerse como una docente empática, muy consciente de que las prioridades en el entorno socioeducativo han cambiado. Ella comenta: "Debo reinventarme a mí misma, reinventarme en el lenguaje, en lo virtual, aunque no es como me gustaría que percibieran a su primera maestra. Esto me hace buscar aprendizaje más situado, buscar que la familia también participe, haciendo adecuaciones para que las actividades no les signifiquen una carga, sino que la disfruten...". Reflexiona también lo siguiente: "No se puede seguir insistiendo en que la prioridad es la educación, cuando existen familias que han sufrido el deceso de varios de sus miembros, familias tanto del alumnado como de los propios compañeros de trabajo. La pandemia me ha significado una reinvención personal" (ESemi2.25032021).

\subsection{Resultados desde el Modelo E-P-R: la influencia del polo relacional}

La revisión de las ocho sesiones ha permitido observar los diálogos establecidos entre la docente y las alumnas, diálogos que, a la luz de la etnografía de la comunicación, son un recurso invaluable sugerido por la didáctica profesional (Vinatier, 2013). El análisis se ha basado en las interacciones orales, recuperando algunos aspectos del lenguaje corporal. Así, este estudio ha permitido reconocer, además de los saberes docentes propuestos en la tipología de Tardif (2010), otros saberes que han emergido en función de la observación y del análisis.

Se hallaron saberes docentes centrados en la importancia de reconocer al niño y sus necesidades, en la búsqueda de aprendizajes situados, en adecuaciones constantes para llegar a los niños de una manera más cercana a pesar de que la interacción esté mediada por una pantalla. Dichos saberes permiten evidenciar una tendencia en su actuar, un esquema que guía a la docente a centrarse en el polo relacional, ese polo que equilibra, que aporta para 
que el polo pragmático tenga mayor efecto bajo las características específicas de las 4 o 5 niñas que se conectaron en promedio.

Así, el polo pragmático fue movilizado por saberes docentes que han invitado a la educadora a formarse y a profundizar en el uso de recursos tecnológicos: juegos, cuentos electrónicos, canciones, personajes virtuales, como mediadores para atraer la atención del alumnado y su implicación en sus procesos de aprendizaje. Entonces el polo epistemológico emerge, pero de manera tácita, en algunos de los comentarios que las niñas hacen. La manera explícita observada con respecto a este polo se presenta durante la recuperación de los conocimientos previos.

Cabe mencionar que el análisis del polo epistemológico no pudo profundizarse. Es un sesgo importante en esta investigación, ya que la evaluación e impacto de las secuencias didácticas en los procesos de aprendizaje de las niñas que lograban conectarse no estaba planteada desde lo pragmático en las sesiones de Zoom. Las evidencias que permitían evaluar de una manera más objetiva los contenidos abordados no eran expuestas en dichas sesiones, eran expuestas en el chat por WhatsApp, mediación pedagógica a la que la investigadora no tuvo acceso.

Otro saber que evidencia el polo relacional es aquel que hace consciente a la docente de su participación en el fomento del rezago educativo al no poder hacer nada en relación con la brecha digital. La educadora se lamenta porque piensa que las estrategias propuestas por la estrategia nacional de la Secretaría de Educación Pública, hasta las propuestas dentro del colectivo docente de su institución, promueven la segregación. La evidencia más contundente es que, de los 12 niños matriculados, hubo una asistencia máxima de 5 niñas, durante todas las observaciones registradas; se hace notar, pues, que nunca se conectó un varón. Las razones generales manifestadas por los padres o madres de familia fueron la falta de recursos tecnológicos y la economía debilitada que les impedía invertir en saldo para datos en su telefonía móvil, situación que evidencia las realidades vividas en muchos países latinoamericanos, tal como lo plantean Southwell (2020) y Johnson (2020).

En relación con la tipología de Tardif (2010), y en cuanto a los saberes docentes que se evidenciaron al contrastar el decir y el hacer, existe consistencia entre lo que se declara en las entrevistas a profundidad y lo que se observa durante las intervenciones docentes, desde lo que Dietz (2017) reconoce como datos verbales y observacionales. 


\section{Conclusiones}

Este estudio ha hecho visibles algunas aristas del quehacer docente y ha permitido, a partir del seguimiento a una educadora diferenciar ciertos detalles, lo que implica hacer docencia en un espacio bajo las características particulares de la modalidad educativa multigrado, urbano-marginada, en la que el contexto social, pero sobre todo el económico, tiene una fuerte influencia en la participación o exclusión de los procesos educativos, situación acentuada por la brecha digital recrudecida desde las demandas propias de la pandemia.

Si bien, las preguntas de investigación han tratado de ser abordadas en los resultados aquí expuestos, también se evidencian sesgos importantes en el manejo del Modelo E-P-R (Vinatier, 2013; Fierro y Fortoul, 2017), ya que el polo epistemológico no pudo apreciarse a profundidad, porque muchas de las evidencias tangibles para conocer los alcances o impacto de la actividad en los procesos de aprendizaje de las niñas participantes no se recuperaron en las secuencias observadas. Es un sesgo generado por la propia distribución en que se ha diseñado este tipo de educación y es algo que no se consideró desde la adaptación metodológica una vez que se transitó al modelo de educación remota. Se considera que la investigadora debió solicitar participar en el chat de WhatsApp, aun solo como observadora.

Otro sesgo importante es el poco tiempo que se dedicó al análisis en colaboración docente-investigadora. Fue difícil concertar citas para hacerlo, porque la educadora tiene una agenda sumamente ocupada debido a su trabajo matutino y en ocasiones no fue posible hacer coincidir las agendas.

El modelo E-P-R permite observar interacciones mediadas por la tecnología, no desde un cara a cara presencial, como lo específica la didáctica profesional -principal referente teórico- (Vinatier, 2013), pero sí con interacciones determinadas por el lenguaje oral, gestual y corporal de quienes participan en el hecho educativo. La pantalla permite visibilizar actitudes, descontentos, emociones, manifestadas ya sea con una palabra o frase, con un gesto o con alguna actitud corporal.

Analizar las prácticas, observar y observarse para descubrir cuáles son los saberes que llevan a hacer el tipo de docencia que se hace y, de ser necesario, redireccionar el actuar, valorar dichos saberes, modificarlos o reforzarlos en la medida de los resultados e implicaciones en los procesos de aprendizaje es una tarea esencial a la que encamina el uso del modelo E-P-R (Vinatier, 2013), sobre todo en la detección honesta de las recurrencias o esquemas que permiten hablar de principios de intervención; lo importante es generar consciencia de los mismos y sus efectos en los procesos de aprendizaje del alumnado. 
El trabajo desde casa debido a la pandemia no ha permitido que los procesos de evaluación se lleven a cabo como se acostumbraba. Este factor fue algo que la investigación debió considerar en el replanteamiento metodológico al transitar a este tipo de educación. Sin embargo, hoy día parece muy necesario aprender a confiar en el otro, a confiar en uno mismo y en sus habilidades para recrear o reinventar una docencia estratégica. Se debe aprender a confiar en lo que se observa en las interacciones mediadas por Zoom, Google Meet o WhatsApp. Confiar en lo que los gestos, diálogos, sonidos y acciones observados a partir de una pantalla demuestran, considerando la ventaja de que dichas interacciones pueden grabarse, lo que garantiza una evidencia del quehacer docente que permite recrear las acciones para analizarlas y reflexionar sobre sus efectos inmediatos en los educandos, tal como lo recomienda la didáctica profesional (Vinatier, 2013).

El paso disruptivo de una educación corporeizada y vivencial a otra de corte virtual, remota, emergente y despersonalizada supone el inicio de un periodo de transición en los procesos de enseñanza y aprendizaje (Loayza-Maturrano, 2020). Este estudio recupera la idea de Quintero (2020), quien reconoce que la manera en que se han atendido los procesos educativos implica aprender en el camino, tal como la profesora y el alumnado van interactuando en escenarios digitales, con muchas dudas en cuanto a cómo manejar todos los recursos que estas tecnologías ofrecen. Ellos son un ejemplo de una situación latente por la cual pasa la educación latinoamericana en plena efervescencia de la pandemia (Alcántara, 2020; Loayza-Maturrano, 2020; Pastran, Gil y Cervantes, 2020).

Hablar de los microescenarios significa sumergirse en las aguas o tratar de cavar profundo en todos aquellos procesos sociales, históricos, culturales, tradicionales, pedagógicos y de gestión de las escuelas con sus entornos inmediatos. Este estudio visibilizó la crudeza que algunos entornos sociales viven, con o sin pandemia. El escenario influenció, mas no determinó las intervenciones docentes. En relación con la violencia suscitada en los últimos años en el entorno del jardín de niños, se reflexiona lo siguiente: hoy la COVID-19 también se ha llevado vidas, no mediante la violencia física o armada, pero sí bajo una amenaza sórdida (cientos de miles de veces devenida en deceso), fundada en el miedo, la incertidumbre y los diversos síntomas que el SARS-CoV-2 ha ido generando mientras se ha instalado como huésped.

El contexto educativo, bajo la emergencia de esta pandemia, implica resignificar los nexos y las influencias que se van entretejiendo en el quehacer cotidiano de los procesos de enseñanza, que hoy día se han debido adecuar al pequeño universo dinámico en el que hace 
más de un año se ha instalado: el hogar. Lo anterior permite visualizar saberes, aquellos respecto de los cuales Tardif (2010) se cuestiona en cuanto a su origen, producción o desarrollo. Habitus que se van generando desde las propias interpretaciones y construcciones que realiza el individuo al relacionarse con su entorno social, al interactuar y empezar a desarrollar vínculos.

La pandemia ha mostrado de una manera contundente la importancia de la participación de los padres, las madres o el familiar que acompaña al niño preescolar en sus procesos formales de enseñanza remota (Loayza-Maturrano, 2020), quienes también han tenido que recrearse y reinventarse en el aprendizaje de ciertas habilidades tecnológicas y de manejo de la información, así como en el replanteamiento de nuevas funciones.

Este confinamiento visibiliza la necesidad de confiar en las estrategias de trabajo colaborativo, en los procesos de evaluación; de buscar colectivos que generen sinergia y promuevan momentos sistemáticos de análisis; momentos que trasciendan en la búsqueda de otro tipo de estrategias para dar seguimiento a los contenidos de la educación básica en México.

La pandemia ha impulsado la generación de procesos creativos en el pensamiento de las maestras y los maestros, quienes, preocupados por acercar las ventajas genuinas de la educación a distancia, pero situada en sus educandos, enarbolan la idea de que este tipo de educación es una oportunidad de cambio social. El caso estudiado es uno de ellos...

\section{Referencias}

Alcántara, Manuel. (2020). La política en América Latina ante la "nueva normalidad". Reflexión Política, 22(45), 9-15. Recuperado de https://revistas.unab.edu.co/index.php/reflexion/article/view/3937

Bertely, María. (2000). Conociendo nuestras escuelas. Un acercamiento etnográfico a la cultura escolar. México: Paidós.

Contreras, Elisa., Cortés, Ana., Daza, Olivia., Martínez-Barradas, Rosa., Sánchez, Tania. y Rivera, Gladys. (2017). La tutoría como estrategia para la formación inicial de educadoras. México: Secretaría de Educación de Veracruz.

Diario Oficial de la Federación. (19 de mayo, 1992). Acuerdo Nacional para la Modernización de la Educación Básica. Recuperado de https://www.sep.gob.mx/work/models/sep1/Resource/b490561c-5c33-4254-ad1caad33765928a/07104.pdf 
Diario Oficial de la Federación. (2006). Reglas de operación del Programa Nacional de Fortalecimiento de la Educación Especial y de la Integración Educativa. Recuperado de http://www.dof.gob.mx/nota detalle popup.php?codigo $=2120660$

Díaz-Barriga Arceo, Frida. (2006). Enseñanza situada: Vínculo entre la escuela y la vida. México: McGraw Hill.

Dietz, Gunther. (2017). La construcción e interpretación de datos etnográficos. En: A. DíazBarriga y C. Domínguez (eds.), Interpretación: un reto en la investigación educativa (pp. 229-262). México: Newton.

Doré, Emilie. (2008). La marginalidad urbana en su contexto: modernización truncada y conductas de los marginales. Sociológica, 23(67), 81-105. Recuperado de http://www.scielo.org.mx/pdf/soc/v23n67/v23n67a5.pdf

Enríquez, Pedro. (2011). El espacio urbano como lugar de marginalidad social y educativa. Argonautas, $\quad$ (1), 48-78. $\quad$ Recuperado de http://www.argonautas.unsl.edu.ar/files/04\%20Enriquez.pdf

Fierro, Cecilia. y Fortoul, Bertha. (2017). Entretejer espacios para aprender y convivir en el aula. México: SM Ediciones.

Gaete, Marcela. (2011). Acciones docentes: saberes en pugna. REXE. Revista de Estudios y Experiencias en Educación, 10(20), 15-34. Recuperado de https://www.redalyc.org/pdf/2431/243122668001.pdf

Galván Luz. (julio, 2019). De las escuelas de párvulos al preescolar. Una historia por contar. Recuperado de http://biblioweb.tic.unam.mx/diccionario/htm/articulos/sec 25.htm

Gil, Numas. (2019). Ambiente virtual de aprendizaje: beneficios y ventajas para enseñanza del francés como L2. Revista Boletín Redipe, 8(11), 91-99. doi: https://doi.org/10.36260/rbr.v8i11.852

Gutiérrez, Francisco. y Prieto, Daniel. (1999). La mediación pedagógica. Apuntes para una educación a distancia alternativa. Buenos Aires: Circus-La Crujía

Instituto Nacional de Estadística y Geografía. (2020). Censo de población y vivienda. México: INEGI. Recuperado de https://www.inegi.org.mx/temas/educacion/

Instituto Nacional para la Evaluación de la Educación. (2010). La educación preescolar en México. Condiciones para la enseñanza y el aprendizaje. México: INEE. Recuperado de https://www.sep.gob.mx/work/models/sep1/Resource/8004/3/images/educacion preesc olar.pdf

Instituto Nacional para la Evaluación de la Educación. (2019). Panorama Educativo de México. Indicadores del Sistema Educativo Nacional 2017. Educación básica y media superior. México: INEE. Recuperado https://publicaciones.inee.edu.mx/buscadorPub/P1/B/116/P1B116.pdf 
Johnson, Daniel. (2020) Coloquio Curriculum Latinoamericano en tiempos de COVID-19: Reacciones $y$ respuestas. [video de youtube]. Recuperado de https://www.youtube.com/watch?v=cNKrmIT7xRs

Loayza-Maturrano, Edward. (2020). Semiótica del discurso docente-discente en la educación remota. Una evaluación semiótico-formativa en tiempos de COVID-19. Revista Científica Hacedor, 4(2), 44-59. Recuperado de http://revistas.uss.edu.pe/index.php/HACEDOR/article/view/1489

Maris, Sônia. y Maciel, Orliney. (2017). Saberes Docentes para o Ensino de Ciências: Um Olhar Sobre a Produção de Professores de Biologia na Formação Continuada. (Informe). Brasil: Programa de Pós Graduação em Educação em Ciências e em Matemática-UFPR. Recuperado http://abrapecnet.org.br/atas enpec/viiienpec/resumos/R0611-2.pdf

Malagón, Javier. (2009). La mediación pedagógica. Mediaciones sociales, (5), 175-180. Recuperado https://revistas.ucm.es/index.php/MESO/article/view/MESO0909220175A/21194

Martínez-Barradas, Rosa. (2017). Los cuatro retos de la educación normal. En M. B. Fortoul (Presidencia), Retos para la formación de los futuros maestros en las escuelas normales ante la política educativa nacional (pp. 22-31). COMIE, San Luis Potosí, México.

Mercado, Ruth. (2014). Los saberes docentes como construcción social. La enseñanza centrada en los niños. México: Fondo de Cultura Económica.

Pastran, María., Gil, Numas. y Cervantes, Derly. (2020). En tiempos de coronavirus: las TIC son una buena alternativa para la educación remota. Revista Boletín Redipe, 9(8), 158165. doi: https://doi.org/10.36260/rbr.v9i8.1048

Peralta, Victoria. y Fujimoto, Gaby. (1998). La atención integral de la primera infancia en América Latina: Ejes centrales y los desafíos para el siglo XXI. Santiago de Chile: Organización de Estados Americanos (OEA).

Poder Ejecutivo. (12 de noviembre de 2002). Decreto por el que se adiciona el artículo $3^{a}$, párrafo primer, fracciones III, V y VI, y el artículo 31 en su fracción I de la Constitución Política de los Estados Unidos Mexicanos. Diario Oficial de la Nación. Poder Ejecutivo. Recuperado https://www.scjn.gob.mx/sites/default/files/cpeum/decretos reformas/201612/00130170.pdf

Quintero, José. (2020). El efecto del COVID-19 en la economía y la educación: estrategias para la educación virtual de Colombia. Revista Scientific, 5(17), 280-291. https://doi.org/10.29394/Scientific.issn.2542-2987.2020.5.17.15.280-291

Redondo, Patricia. y Thisted, Sofía. (1997). Mitos y realidades de las escuelas de los márgenes. Trabajo presentado en el Primer Congreso Internacional Pobres y pobreza en la sociedad argentina. Universidad Nacional de Quilmes y CONICET. Recuperado de https://www.equiponaya.com.ar/congresos/contenido/quilmes/P1/31.htm 
Secretaría de Educación de Veracruz. (2019). Prontuario estadístico. Ciclo escolar 2019-2020. Recuperado de http://www.sev.gob.mx/upece/wp-content/uploads/2020/06/Prontuarioinicio-de-cursos-2019-2020.pdf

Secretaría de Educación Pública (SEP). (1992). Programa de Educación Preescolar 1992. México: SEP.

Secretaría de Educación Pública (SEP). (2002). Programa Nacional de Fortalecimiento de la educación especial y de la integración educativa. México: SEP.

Secretaría de Educación Pública (SEP). (2004). Programa de Educación Preescolar 2004. México: SEP.

Secretaría de Educación Pública (SEP). (2011). Programa de estudio 2011. Guía para la educadora. Educación Básica. Preescolar. México: SEP.

Secretaría de Educación Pública (SEP). (2017). Aprendizajes clave para la educación integral. Educación preescolar. Plan y programas de estudio, orientaciones didácticas y sugerencias de evaluación. México: SEP.

Southwell, Miriam. (2020). Coloquio Currículum Latinoamericano en tiempos de COVID-19: Reacciones $y$ respuestas. [video de youtube]. Recuperado de https://www.youtube.com/watch?v=cNKrmlT7xRs

Tardif, Maurice. (2010). Los saberes del docente y su desarrollo profesional. España: Narcea.

Tenti, Emilio. (1997). La escuela vacía: deberes del estado y responsabilidades de la sociedad. Buenos Aires: Losada.

Vinatier, Isabel. (2013). Le travail de l'enseignant. Une approche par la didactique professionnelle. Bruxelles: De Boeck Éducation.

Yin, Robert. (1994). Case Study Research: Design and Methods. Sage Publications: Thousand Oaks, CA. 
Revista indizada en
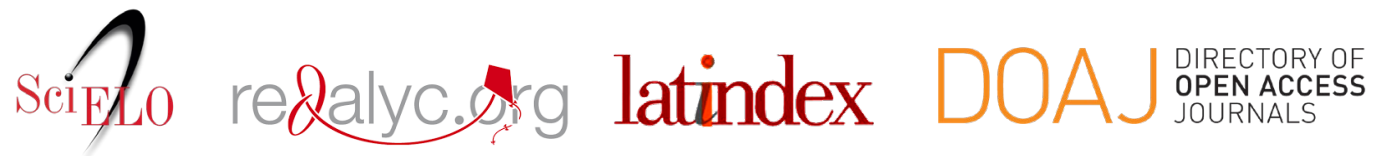

Distribuida en las bases de datos:
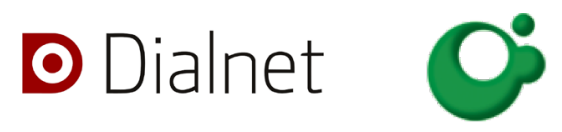
SHERPA/RøMEO

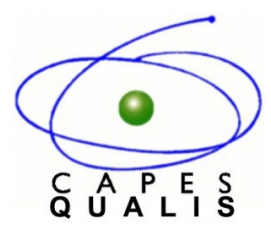

MIAR 